\title{
Accounting for greenhouse gas emissions from traffic rearrangement: a network vulnerability perspective
}

\author{
George Vasconcelos Goes ${ }^{\text {a* }}$ (D), Márcio de Almeida D’Agosto ${ }^{\mathrm{a}}$ (D), \\ Pedro Henrique de Castro Albuquerque Machado \\ anniversidade Federal do Rio de Janeiro, Instituto Alberto Luiz Coimbra de Pós-graduação e Pesquisa de Engenharia, \\ Departamento de Engenharia de Transportes, Rio de Janeiro, RJ, Brasil
}

*ggoes@pet.coppe.ufrj.br

\begin{abstract}
Paper aims: This study aims to accounting for greenhouse gas emissions from traffic rearrangement, using a network vulnerability framework.

Originality: We present a new procedure to verify the effectiveness of accident risk as an attribute to find the most vulnerable links of a road network, estimating the amount emitted in the process.

Research method: Vulnerability is measured by the variation in $\mathrm{CO}_{2}$ equivalent emitted and total distance traveled, after changes in accessibility patterns.

Main findings: To date, limited research exists on accounting for emissions from the perspective of vulnerability. Three scenarios of risk-level and traffic conditions were modeled. Results indicate that high levels of accidents exposure may increase emissions by 5.2\% compared to a low-risk scenario, and 9.1\% compared to an unabridged network scenario.
\end{abstract}

Implications for theory and practice: The proposed framework could support governmental policies and urban planning to verify the impact of accessibility patterns in GHG emissions.

Keywords

Greenhouse gas. Emissions. Vulnerability. Risk.

How to cite this article: Goes, G. V., D’Agosto, M. A., \& Machado, P. H. C. A. (2019). Accounting for greenhouse gas emissions from traffic rearrangement: a network vulnerability perspective. Production, 29, e20190015. https://doi.org/10.1590/0103-6513.20190015.

Received: Mar. 11, 2019; Accepted: June 10, 2019.

\section{Introduction}

The increase in freight transportation intensity has changed the frequency and duration of traffic congestion in densely populated areas. To mitigate costs, transport systems are often configured to operate close to their capacity (Mattsson \& Jenelius, 2015). Occasional disturbances in the road network (e.g. traffic accidents, traffic congestions, flooding) may lead to impacts over economic, social and environmental aspects, which are initially perceived by users as traffic congestions.

Indeed, contemporary governmental policies have focused on mobility and land use. Nonetheless, there are still negative externalities related to urban transportation, especially the intensification of individual motorized transport and the use of fossil-fueled vehicles, expanding traffic volume in the road network and greenhouse gas (GHG) emissions. Thus, travel demand has been upward at a highly statistically significant rate, imposing pressure on system's capacity (Bevrani et al., 2017). This phenomenon has major implications on energy use and GHG emissions into the atmosphere (Lyons \& Davidson, 2016).

Literature defines two types of traffic congestions: (1) recurring, whether it depends on traffic flows and density; and (2) non-recurring, when it is the result of external events, such as an traffic accident (Conca et al., 2016). 
To create a robust and reliable transportation system, it is important to understand the mechanisms and interrelationships that can better engender disaster recovery, turning it more resilient to disturbances (Mattsson \& Jenelius, 2015).

The assessment of road network vulnerability involves fundamentally: links disruptions or capacity reduction; and impacts on travel time and costs (Jenelius \& Mattsson, 2012). Along these lines, there are methods in the literature that can be conducted, which are divided into two groups (Knoop et al., 2012). The first group contains the complete calculation methods, in which all links are disrupted, and the road network is scanned to find out which links are most critical in case of disasters. The second group uses pre-defined criteria for searching the most vulnerable links. In this approach, we first select links that are possibly vulnerable, based on specific characteristics (e.g. land use, topology, accessibility conditions, disasters historical). After that, a more detailed analysis is conducted by disrupting the selected links.

Adopting methods that fit into the second group is interesting from the point of view of network modeling, in order to reduce iterations when simulating the experiment (Goes \& Bertoncini, 2016). It is possible to identify critical links of the road network in an indirect way. For road networks in densely populated areas, the use of these methods can lead to cost savings.

There are several studies that relate climate change to vulnerability of urban areas (Füssel \& Klein, 2006; Althor et al., 2016; Davis \& Vincent, 2017), however, usually the basic elements of analysis rely on adapting cities to sea level rise or flooding. In other words, studies involving the GHG emitted from traffic rearrangement after a random disturbance are scarce in the literature.

Considering these research gaps, this study aims to accounting for GHG from traffic rearrangement, using a network vulnerability framework. Specifically, we conduct a vulnerability assessment from a pre-defined criterion of risk (road-traffic crashes). Here, vulnerability is measured in terms of distance increase and $\mathrm{CO}_{2}$ equivalent emissions $\left(\mathrm{CO}_{2} \mathrm{e}\right)$.

To identify in the specialized literature which risk factors, metrics and methods are being used in vulnerability assessments, we conduct a systematic literature review on vulnerability, aiming to summarize the results of previous researches.

Apart from this introduction, this paper is divided into six sections. Section 2 discusses the concept of risk. Section 3 summarizes the systematic literature review. Section 4 discusses the procedure developed in this research to analyze the vulnerability of a road network. Section 5 shows the experiment and analyses results. Section 6 concludes the study and presents recommendations for future work.

\section{Literature review}

Risk estimative is based on the chances of a random event occurring and its consequences (Faturechi \& Miller-Hooks, 2014). We opted to evaluate the risk of road-traffic crashes, developing a method based on the study of Haimes (1998), which is still pertinent to contemporary transport-related problems.

Thus, the expected value of risk is essentially the product of the consequences of each threat by the chances of occurrence. After that, we summarize all products in the universe of possible events. For each conceivable risk scenario, the assessment can be structured as a "triplet": (1) scenario description; (2) probability; and (3) measurement of damage (Mattsson \& Jenelius, 2015).

Here, consequences are related to socio-environmental and economic aspects. In relation to the probability and exposure to traffic accidents, literature points to crash prediction models that seek to measure the exposure to accidents in a particular link or intersection, using variables that can explain the risk exposure (Cardoso \& Goldner, 2007).

On the other hand, vulnerability assessments consider the consequences on system performance after several links or nodes disruptions (Faturechi \& Miller-Hooks, 2014). Therefore, the vulnerability of transportation network can be seen as a problem of reduced accessibility (Chen et al., 2007).

Impedances in transportation-related models consider variables of distance, monetary value etc. (Jenelius et al., 2006), however, the use of travel time is the most widespread variable in vulnerability assessments. Literature suggests that changes in travel time have equivalent effects on trip cost (Altiparmak et al., 2006; Gen et al., 2006; Taylor et al., 2006; Sullivan et al., 2010).

Regarding GHG emissions, there are several studies that calculate emissions from counties, but most focuses on aggregate amount of $\mathrm{GHG}$ emitted from the different activities that support city functioning (Romero-Lankao \& Dodman, 2011). The approaches to estimate emissions from traffic varies across countries and usually depend on the country's infrastructure and road network design. 
For aggregate results, studies conventionally adopt a top-down approach, which require the information of overall energy consumption from transport activities. In turn, to measure emissions using a disaggregated approach (bottom-up), it is important to consider the sum of all vehicles that are in use in a specific time interval (Brasil, 2014, 2016).

The use of disaggregated approaches for carbon emissions calculations provides a higher level of details, enhancing the analysis results. For this reason, we opted to use a bottom-up approach, described in the study of Intergovernmental Panel on Climate Change (2006) and applied in the study of Brasil (2014).

Considering these researches fields, we conducted a systematic review protocol to identify researches gaps in the literature regarding the use of road-traffic crashes risk and GHG emissions during the process of vulnerability assessment. The review protocol is based on the study of Thomé et al. (2016). The search was conducted in the Web of Science database, considering the following strings: "vulnerability" AND "transport*" OR "freight" AND ("exposure" OR "risk"), applied to the title, abstract and keywords over the last 10 years.

Studies related to vulnerability assessment, but not specifically to accessibility of transportation network, were not included. Hence, the selected studies were evaluated according to the criteria:

- Phenomenon: congestion, natural disaster, traffic accidents or closure;

- Scenario scale: urban or regional;

- Metric: complete calculations (all links are disrupted); group of links (predefined criteria);

- Method: Statistical analysis (parametric and non-parametric models, regression analysis and risk models); Probabilistic model (dynamic modeling and Bayesian networks); Theory of complex networks (e.g. graph theory) and Simulation (e.g. Monte Carlo);

- Environmental aspects: estimates emissions of GHG or atmospheric pollutants.

Table 1 summarizes the results. None of the studies addresses vulnerability under the scope of GHG emissions. One of the possible arguments is that when assessing the vulnerability most studies consider the adaptation perspective due to climate changes or recurrent disasters. Which means that few studies exploit the GHG mitigation from changes in traffic patterns.

Only two studies deal with the use of pre-defined criteria for searching the most vulnerable links. Moreover, only one article considers traffic accidents as a phenomenon responsible for link disruptions in vulnerability assessments but did not simulated the effects.

As a matter of fact, besides considering travel time and distance, this study also inserts GHG emissions derived from traffic rearrangement after a link disruption, which contributes to mitigation and adaptation policies at micro-and meso-scales. Table 1 summarizes the results.

Table 1. Review results.

\begin{tabular}{lllll}
\hline \multicolumn{1}{c}{ Author } & Phenomenon & Scale & Metric & Method \\
\hline Knoop et al. (2007) & Closure & Regional & Full Calculation Methods & $\begin{array}{c}\text { Simulation } \\
\text { Aspects }\end{array}$ \\
$\begin{array}{l}\text { Luathep et al. (2011) } \\
\text { Demirel et al. (2015) }\end{array}$ & Congestion & Urban & Full Calculation Methods & Complex Networks Theory \\
Ambituuni et al. (2015) & Natural disasters & Regional & Pre-defined criteria & Simulation \\
Kermanshah \& Derrible (2016) & Traffic accidents & Regional & Pre-defined criteria & Probabilistic Modeling \\
lnanloo et al. (2016) & Congestion & Urban & Travel Time & Simulation \\
Muriel-Villegas et al. (2016) & Natural disasters & Urban & Travel Time & Probabilistic Modeling \\
Asadabadi \& Miller-Hooks (2017) & Natural disasters & Urban & Travel Time & Probabilistic Modeling \\
Thorisson \& Lambert (2017) & Traffic accidents & Urban & Travel Time & Probabilistic Modeling \\
Fialkoff et al. (2017) & Congestion & Regional & Travel Time & Statistical Analysis \\
\hline
\end{tabular}

\section{Method}

Figure 1 illustrates the methodological steps to account carbon emissions from traffic accidents, evaluating the road network vulnerability. The procedure is focused on urban road networks with the presence of traffic congestions. 

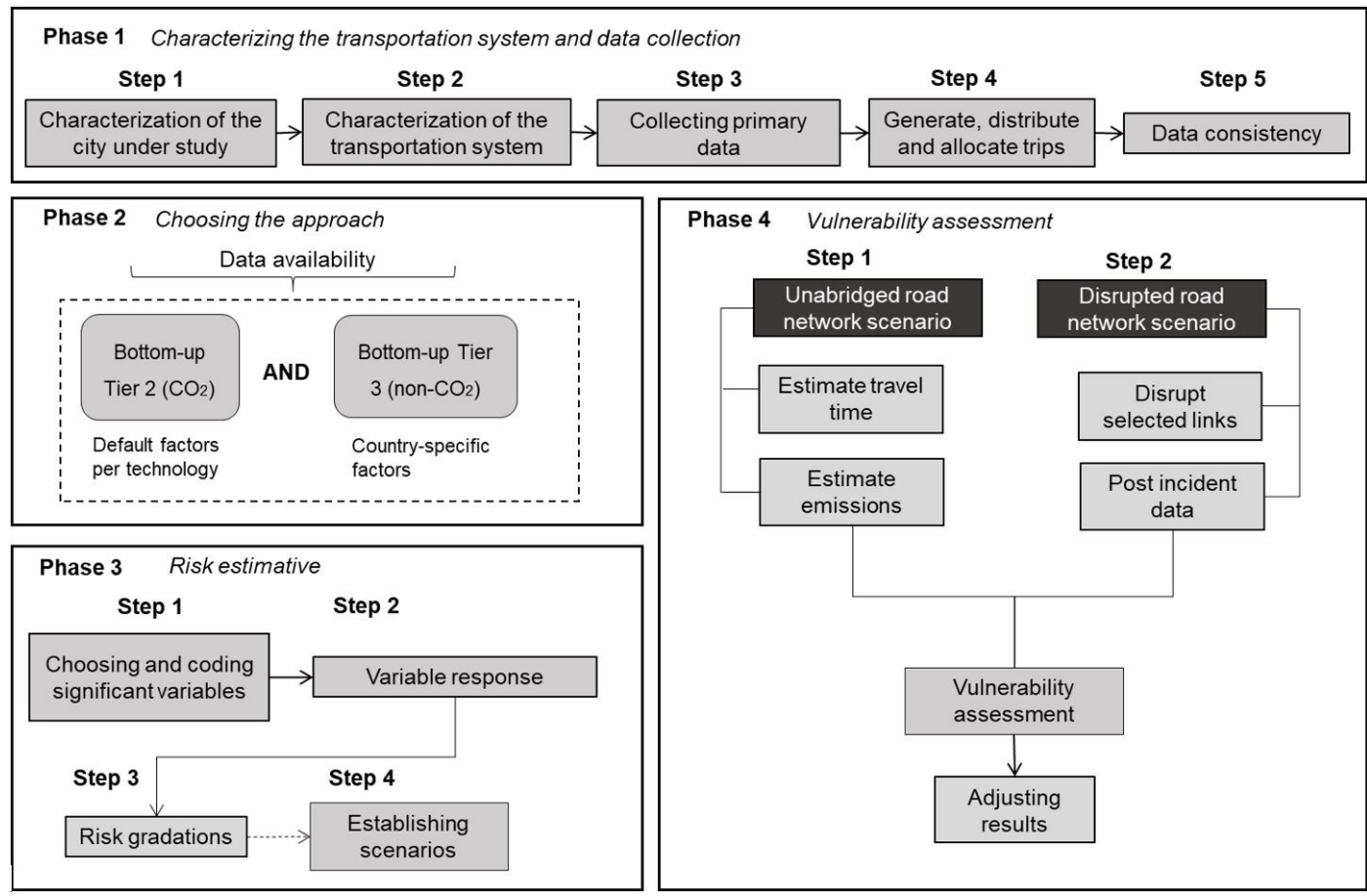

Figure 1. Assessment procedure considering accident risk and emissions.

The fundamental phases to account emissions from the perspective of vulnerability are: (1) Characterizing the transportation system and data collection; (2) Choosing data approach; (3) Risk estimative; and (4) Vulnerability assessment.

\subsection{Scenario description}

The experiment was conducted in a densely populated area of Fortaleza, Brazil. In addition, it is close to industrialized zones and strategic delivery bases. In Brazil, there are not well-structured national vehicle licensing records to provide information about vehicles counts per model-year that are in fact being used and where they are located. There is no official data on transport activity per year and transportation mode either. For these reasons some assumptions were adopted.

First, we considered three different traffic flow rates: 1,000, 1,250, and 1,500 vehicles per hour (vph), depending on the characteristic of the street (Colella et al., 2004; Karim \& Adeli, 2002). The speed limits are: $40 \mathrm{~km} / \mathrm{h}$ (collector) and $60 \mathrm{~km} / \mathrm{h}$ (arterial). All emissions are reported according to a time period of one hour.

According to these features, travel time for each link under free-flowing traffic is approximately 0.1 minute (arterial street) and 0.16 minute (collector street). Figure 2 illustrates the experiment area.

We used a deterministic equilibrium protocol to assign traffic onto the network. This calculation was also used by reference studies as Jenelius et al. (2006), Scott et al. (2006), Tampère et al. (2008), Sullivan et al. (2010), and Huang et al. (2012). Therefore, we assume that users look for paths that minimize their costs based on the perception of travel time.

Travel time was estimated according to Equation 1, proposed by the Bureau of Public Roads (BPR), specifically in NCHRP 365 (Transportation Research Board, 1998).

$$
t_{a}=t_{0, a}\left[1+b\left(\frac{f_{a}}{\operatorname{cap}_{a}}\right)^{y}\right]
$$

where: $t_{a}=$ travel time on link $a ; t_{0, a}=$ travel time on link $a$ (free-flow); fa = flow over link $a$; cap $p_{a}=$ capacity of link $a ; y=$ constant; $b=$ constant. 

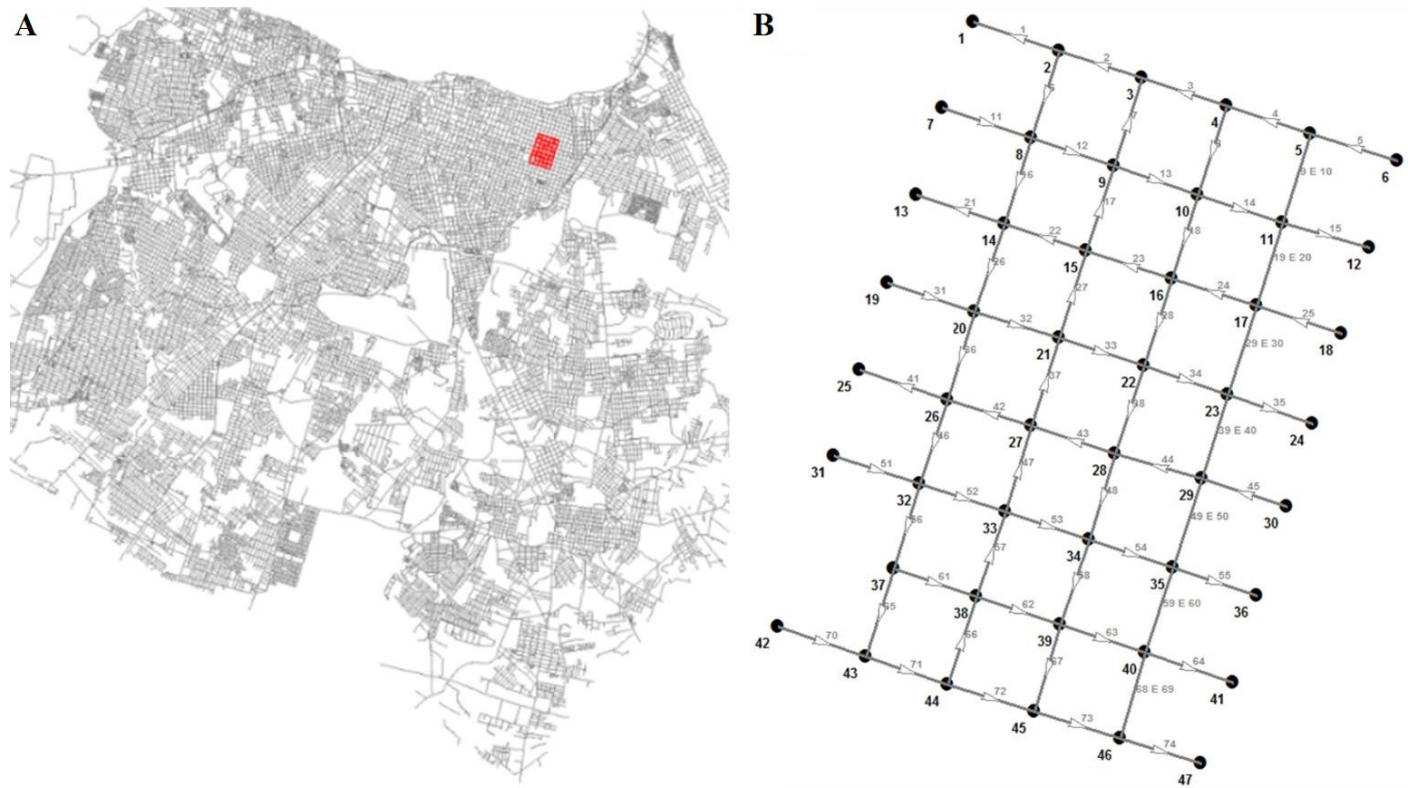

Figure 2. (A) Complete road network; (B) Area of the experiment.

We adopted the values of 4 and 0.15 for constants $y$ and $b$. These values were suggested by the BPR engineers and widely used in traffic engineering analysis, such as Wang (2005) and Yin \& Lawphongpanich (2006), which conducted network robustness studies applied to cities from developing countries.

\subsection{Unabridged road network scenario}

We considered the following GHG: carbon dioxide $\left(\mathrm{CO}_{2}\right)$, methane $\left(\mathrm{CH}_{4}\right)$ and nitrous oxide $\left(\mathrm{N}_{2} \mathrm{O}\right)$, which are direct GHG presented in most of national sectoral reports (Brasil, 2014, 2016). The emission factors of $\mathrm{CO}_{2}(2.60 \mathrm{~kg} / \mathrm{l}), \mathrm{CH}_{4}(0.06 \mathrm{~g} / \mathrm{km})$ and $\mathrm{N}_{2} \mathrm{O}(0.03 \mathrm{~g} / \mathrm{km})$ were obtained in the study of Companhia Ambiental do Estado de São Paulo (2017).

It is important to state that emissions factors from $\mathrm{GHG}$ non- $\mathrm{CO}_{2}$ are local and vary according to the vehicle technology, which means that they require a bottom-up Tier 3 approach to account emissions. Also, $\mathrm{CO}_{2}$ is estimated based on local emission factors, although they do not vary according to the vehicle-technology, which represents a bottom-up Tier 2 approach (Intergovernmental Panel on Climate Change, 2006). Nonetheless, Tier 1 and Tier 2 are considered as higher-level approaches (European Environment Agency, 2016).

Fuel economy was estimated based on field data and Companhia Ambiental do Estado de São Paulo (2017). Emissions data were converted into $\mathrm{CO}_{2} \mathrm{e}$ by measuring the global warming potential (GWP) of each gas, considering the Fifth Assessment Report (AR5), periodically revised by the Intergovernmental Panel on Climate Change (IPCC) (Myhre et al., 2013).

To estimate the road-traffic crashes risk, we adopted the crash prediction model developed by Cardoso \& Goldner (2007), composed by all steps from Phase 3, presented in Figure 1. The model is based on two fundamental equations, which require the identification and collection of risk variables.

Along these lines, the significant variables identified are: (1) daily average volume of vehicles (Vol_Ve); and (ii) average speed (Sp_Ve). Primary values of these variables were simulated by modeling the network and applying the Equation 1.

The next step was based on coding the collected variables to the same numerical basis using the Equation 2 .

$$
V c o d=\frac{V o b s-A}{B-A}
$$

wherein: $V_{\text {cod }}=$ coded value of the variable (ranging from 0 to 1); $V_{\text {obs }}=$ observed value of the variable; $A=$ lowest observed value of the sample; $B=$ highest observed value of the sample. 
Then, the coded variables of risk exposure (significant variables) were inserted in the crash prediction function, represented by Equation 3.

$$
V R=e^{\left(b_{0}+\sum_{i=1}^{n} b_{i} x_{i}\right)}
$$

wherein: $V R=$ variable response; $e=$ Euler's number; $b_{o}=$ constant $; b_{i}=$ model parameters; $x_{i}=$ significant variables (risk factors).

We adopted the value of $1.4338\left(b_{0}\right)$ and 0.7724 for the parameter $b$ associated with the "daily average volume of vehicles" variable. For the variable "average speed", we adopted the same constant $b_{0}(1.4338)$ and the value of 0.4388 for the parameter $b$. These are the same measures suggested by Cardoso \& Goldner (2007).

Moreover, these outputs are important to establish a gradation of risk (high, average and low) of each road network link considering the variables adopted.

\subsection{Disrupted road network scenario}

In summary, 32 scenarios of links disruption from traffic accidents were simulated. From this, 16 disruptions were conducted in high-risk links, while the other 16 were conducted in low-risk links. Table 2 shows the variable response (VR) of each network link.

Table 2. Variable response by link.

\begin{tabular}{|c|c|c|}
\hline Links & $\begin{array}{l}\text { Variable } \\
\text { response }\end{array}$ & $\begin{array}{c}\text { Gradation of } \\
\text { risk }\end{array}$ \\
\hline $9 ; 10 ; 11 ; 12 ; 13 ; 14 ; 15 ; 19 ; 20 ; 21 ; 22 ; 23 ; 24 ; 25 ; 29 ; 30 ; 32 ; 33 ; 34 ; 35 ; 39 ; 40 ; 49 ; 50 ; 57 ; 59 ; 60 ; 61 ; 62 ; 63 ; 64 ; 68 ; 69$. & $\mathrm{VR} \leq 18$ & Low \\
\hline $1 ; 2 ; 3 ; 5 ; 6 ; 7 ; 8 ; 16 ; 18 ; 26 ; 27 ; 28 ; 31 ; 36 ; 37 ; 38 ; 41 ; 46 ; 48 ; 53 ; 54 ; 56 ; 58 ; 67 ; 72$. & $18<\mathrm{VR} \leq 25$ & Average \\
\hline 5;17;42;43;44;45;47;51;52;55;65;66;70;71;73;74. & $25<\mathrm{VR}$ & High \\
\hline
\end{tabular}

The protocol to establish the gradation of risk of each road network link was adapted from Budetta \& Nappi (2013). Each VR was pondered by the traffic volume of the respective link, adding consistence to the outputs.

The assessment of vulnerability is conducted by the variation of traveled mileage and $\mathrm{CO2e}$ emissions. Table 3 shows the values of average mileage and emissions obtained from the 16 disruptions (n) conducted in each scenario.

In order to simulate the effects over time, we also employed a Monte Carlo simulation, assuming that the phenomenon can be represented by a normal distribution.

Table 3. Input parameters for Monte Carlo simulation.

\begin{tabular}{lcccc}
\multicolumn{1}{c}{ Scenarios } & Emission $\mathrm{CO}_{2} \mathrm{e}(\mathrm{kg})$ & Standard deviation & Traveled distance $(\mathrm{km})$ & Standard deviation \\
\hline Unabridged road network & $1,192.81$ & - & $2,285.25$ & - \\
Scenario $1^{1}$ & $\mu^{3}=1,291.70$ & $\sigma=71.10$ & $\mu=2,474.71$ & $\sigma=136.23$ \\
Scenario $2^{2}$ & $\mu=1,227.61$ & $\sigma=49.76$ & $\mu=2,351.93$ & $\sigma=95.33$ \\
\hline
\end{tabular}

'Data collection of links with high accident risk $(n=16)$; ${ }^{2}$ Data collection of links with low accident risk $(n=16)$; ${ }^{3}$ Expected mean values.

\section{Discussion}

Figure $3 \mathrm{~A}$ compares the $\mathrm{CO}_{2}$ e emitted by the traffic when disrupting links of low-risk scenarios and high-risk scenarios. It should be noted that both fundamental outputs $\left(\mathrm{CO}_{2} \mathrm{e}\right.$ and distance traveled) vary more in high-risk scenarios. This trend can also be observed in Figure $3 \mathrm{~B}$, which represents the $\mathrm{CO}_{2} \mathrm{e}$ emissions over time. In this case, 1,000 iterations were simulated.

Table 4 summarizes the results for both scenarios. In the first case, $\mathrm{CO}_{2} \mathrm{e}$ varies up to $9.19 \%$ compared to the unabridged network scenario, while the mileage traveled varied until 8.51\%. In the second case, $\mathrm{CO}_{2}$ e emissions increased 5.54\% and distance traveled $2.38 \%$ respectively.

In the unabridged road network scenario, the total emission of $\mathrm{CO}_{2}$ e reaches $1,192.81 \mathrm{~kg}$ in a time period of one hour. In the other two scenarios, total amount emitted are $1,302.48 \mathrm{~kg}$ and $1,258.83 \mathrm{~kg}$ respectively. Moreover, emissions occurred by traffic rearrangement from changes in accessibility patterns are 109,67 kg (Scenario 1) and 66,02 kg (Scenario 2). This information can support resilience assessments of megacities, in which traffic volume suffers constant changes from several disturbances Nagpure et al. (2013). 


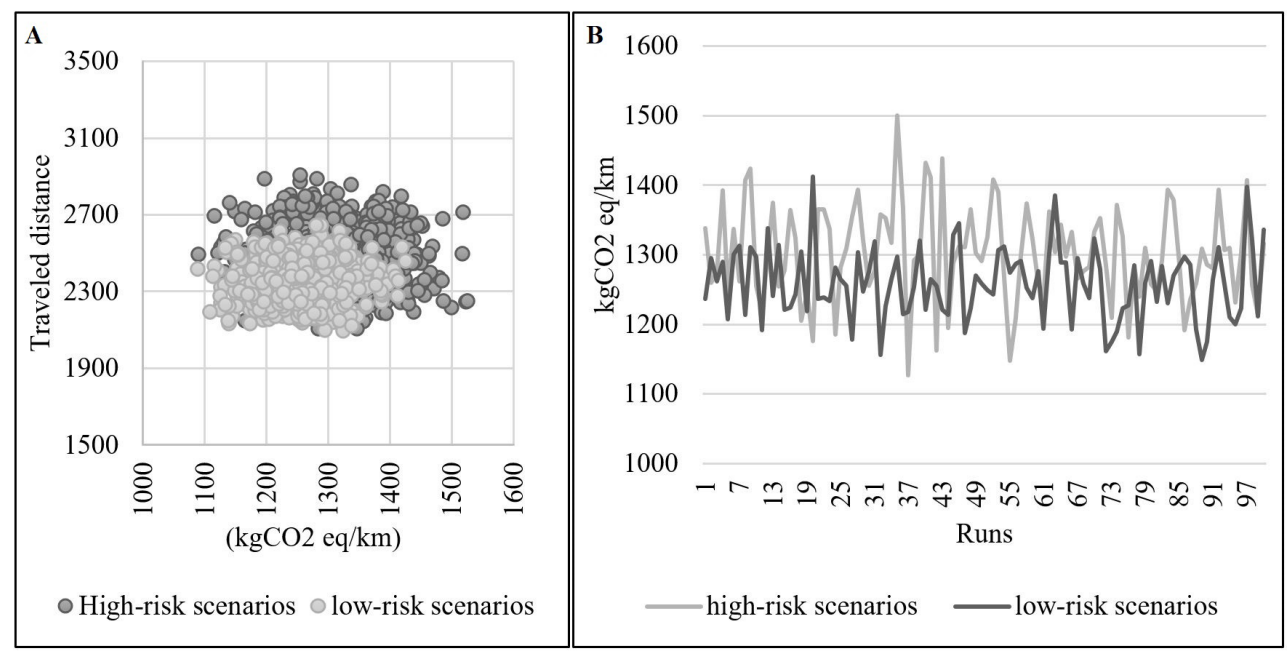

Figure 3. (A) Traveled distance vs $\mathrm{CO}_{2}$ e emissions by scenario; (B) Simulation of $\mathrm{CO}_{2}$ e emissions over.

Table 4. Monte Carlo simulation results.

\begin{tabular}{lcccc}
\hline \multicolumn{1}{c}{ Scenarios } & Emission $\mathrm{CO}_{2} \mathrm{e}(\mathrm{kg})$ & Change $(\%)^{3}$ & Traveled distance $(\mathrm{km})$ & Change $(\%)$ \\
\hline Unabridged road network & $1,192.81$ & - & $2,285.25$ & - \\
Scenario $1^{\prime}$ & $\mu=1,302.48$ & 9.19 & $\mu=2,479.70$ & 8.51 \\
Scenario $2^{2}$ & $\mu=1,258.83$ & 5.54 & $\mu=2,339.66$ & 2.38 \\
\hline
\end{tabular}

${ }^{1}$ High road-traffic crashes risk; ${ }^{2}$ Low road-traffic crashes risk; ${ }^{3}$ Variation in relation to the Unabridged road network scenario.

Table 4 summarizes the results for both scenarios. In the first case, $\mathrm{CO}_{2}$ e varies up to $9.19 \%$ compared to the unabridged network scenario, while the mileage traveled varied until $8.51 \%$. In the second case, $\mathrm{CO}_{2}$ e emissions increased 5.54\% and distance traveled 2.38\% respectively.

Scenario 1 presented a greater variation that can be explained by the significant variables adopted in the crash prediction model (Vol_Ve and Sp_Ve). In other words, the daily traffic volume is more significative in predicting accident risk.

In the experiment, links with high-risk of traffic accident are located in areas with high economic activity levels, which generates and attracts more trips. When these links are disrupted, they may affect a greater number of users, increasing the distance traveled in the network.

When assessing GHG emissions, the simulation showed that $\mathrm{CO}_{2}$ e emissions are significant in case of high-risk links, since the distance traveled increases in the same proportion.

As a result, there are indications that road-traffic crashes risk is directly related to the most vulnerable links of an urban road network. Moreover, GHG emissions are directly related to traffic accidents, and the effect can be significant in greater networks or even at regional scale.

\section{Conclusions and policy implications}

This study aimed to accounting for GHG from traffic rearrangement, using a network vulnerability framework. Specifically, we conducted a vulnerability assessment from a pre-defined criterion of risk (road-traffic crashes). Vulnerability was measured in terms of distance increase and $\mathrm{CO}_{2}$ equivalent emissions $\left(\mathrm{CO}_{2} \mathrm{e}\right)$.

The literature review indicated opportunities related to the use of traffic accident as pre-defined criteria to find the most vulnerable links of an urban road network. These results contribute to the study of Knoop et al. (2012), specifically in the use of pre-defined criteria to find the most vulnerable links of an urban road network.

No article addressed the GHG emissions from path changes after a link disruption as a mitigation measure that could be further employed in governmental policies. These preliminary conclusions attest another innovative contribution of this work.

In addition, we observed that mileage traveled, observed in scenario 1, varies up to $8.51 \%$ compared to the unabridged network scenario. On the other hand, mileage traveled of low-risk scenarios varies only $2.38 \%$ in 
case of disruption. As a matter of fact, $\mathrm{CO}_{2}$ e emissions presented the same trend: high-risk scenarios varied up to $9.19 \%(109.67 \mathrm{~kg})$ and low-risk scenarios varied only $5.54 \%(66.02 \mathrm{~kg})$ in case of disturbance.

Despite the experiment being conducted in a restricted area, the number of scenarios modeled were effective in simulating disruptions under various scenarios of uncertainties. Moreover, the procedure proved to be feasible in verifying the effect of traffic accidents in municipal GHG emissions.

This study may support others researches from cities with different characteristics and backgrounds. It would be possible to develop benchmarking studies to determine the best actions on GHG mitigation regarding traffic rearrangement, under various political and economic contexts.

For future research, we recommend employing the model in a larger network, to assess the actual impact of traffic accidents on municipal GHG emissions. This could support long-term assessment of network robustness improvements and explain how it could mitigate emissions in microscale traffic simulation.

\section{References}

Althor, G., Watson, J. E., \& Fuller, R. A. (2016). Global mismatch between greenhouse gas emissions and the burden of climate change. Scientific Reports, 6(1), 20281. http://dx.doi.org/10.1038/srep20281. PMid:26848052.

Altiparmak, F., Gen, M., Lin, L., \& Paksoy, T. (2006). A genetic algorithm approach for multi-objective optimization of supply chain networks. Computers \& Industrial Engineering, 51(1), 196-215. http://dx.doi.org/10.1016/j.cie.2006.07.011.

Ambituuni, A., Amezaga, J. M., \& Werner, D. (2015). Risk assessment of petroleum product transportation by road: a framework for regulatory improvement. Safety Science, 79, 324-335. http://dx.doi.org/10.1016/j.ssci.2015.06.022.

Asadabadi, A., \& Miller-Hooks, E. (2017). Assessing strategies for protecting transportation infrastructure from an uncertain climate future. Transportation Research Part A, Policy and Practice, 105, 27-41. http://dx.doi.org/10.1016/j.tra.2017.08.010.

Bevrani, B., Burdett, R. L., Bhaskar, A., \& Yarlagadda, P. K. D. V. (2017). A capacity assessment approach for multi-modal transportation systems. European Journal of Operational Research, 263(3), 864-878. http://dx.doi.org/10.1016/j.ejor.2017.05.007.

Brasil, Ministério do Meio Ambiente - MMA. (2014). Inventário nacional de emissões atmosféricas por veículos automotores rodoviários. Brasília: MMA.

Brasil, Ministério de Ciência, Tecnologia e lnovação - MCT1. (2016). Terceira comunicação nacional do Brasil à Convenção-Quadro das Nações Unidas sobre Mudança do Clima (Vol. 2). Brasília: MCTl.

Budetta, P., \& Nappi, M. (2013). Comparison between qualitative rockfall risk rating systems for a road affected by high traffic intensity. Natural Hazards and Earth System Sciences, 13(6), 1643-1653. http://dx.doi.org/10.5194/nhess-13-1643-2013.

Cardoso, G., \& Goldner, L. G. (2007). Desenvolvimento e aplicação de modelos para previsão de acidentes de trânsito. Transportes, 15(2), 43-51. http://dx.doi.org/10.14295/transportes.v15i2.35.

Chen, A., Yang, C., Kongsomsaksakul, S., \& Lee, M. (2007). Network-based accessibility measures for vulnerability analysis of degradable transportation networks. Networks and Spatial Economics, 7(3), 241-256. http://dx.doi.org/10.1007/s11067-006-9012-5.

Colella, D. A. T., Lima, E. P., \& Demarchi, S. H. (2004) Calibração e validação do modelo fluxo-velocidade do lntegration para vias urbanas semaforizadas. In Anais do XVIII Congresso de Pesquisa e Ensino em Transportes (Vol. 1, pp. 453-564). Florianópolis: Associação Nacional de Pesquisa e Ensino em Transportes.

Companhia Ambiental do Estado de São Paulo - CETESB. (2017). Vehicle emissions in the state of São Paulo 2016. São Paulo: CETESB.

Conca, A., Ridella, C., \& Sapori, E. (2016). A risk assessment for road transportation of dangerous goods: a routing solution. Transportation Research Procedia, 14, 2890-2899. http://dx.doi.org/10.1016/j.trpro.2016.05.407.

Davis, C. L., \& Vincent, K. (2017). Climate risk and vulnerability: a handbook for Southern Africa. Pretoria: CSIR.

Demirel, H., Kompil, M., \& Nemry, F. (2015). A framework to analyze the vulnerability of European road networks due to Sea-Level Rise (SLR) and sea storm surges. Transportation Research Part A, Policy and Practice, 81, 62-76. http://dx.doi.org/10.1016/j.tra.2015.05.002.

European Environment Agency - EEA. (2016). EMEP/EEA air pollutant emission inventory guidebook 2016: technical guidance to prepare national emission inventories (pp. 1-20). Copenhagen: EEA.

Faturechi, R., \& Miller-Hooks, E. (2014). Measuring the performance of transportation infrastructure systems in disasters: a comprehensive review. Journal of Infrastructure Systems, 21(1), 1-15. http://dx.doi.org/10.1061/(ASCE)IS.1943-555X.0000212.

Fialkoff, M. R., Omitaomu, 0. A., Peterson, S. K., \& Tuttle, M. A. (2017). Using geographic information science to evaluate legal restrictions on freight transportation routing in disruptive scenarios. International Journal of Critical Infrastructure Protection, 17, 60-74. http://dx.doi.org/10.1016/j.jicip.2016.12.001.

Füssel, H. M., \& Klein, R. J. (2006). Climate change vulnerability assessments: an evolution of conceptual thinking. Climatic Change, 75(3), 301-329. http://dx.doi.org/10.1007/s10584-006-0329-3.

Gen, M., Altiparmak, F., \& Lin, L. (2006). A genetic algorithm for two-stage transportation problem using priority-based encoding. OR-Spektrum, 28(3), 337-354. http://dx.doi.org/10.1007/s00291-005-0029-9.

Goes, G. V., \& Bertoncini, B. V. (2016). Modelo de estimação de custos do transporte urbano de cargas com base na vulnerabilidade da rede viária. Journal of Transport Literature, 10(2), 30-34. http://dx.doi.org/10.1590/2238-1031.jtl.v10n2a6.

Haimes, Y. Y. (1998). Risk modeling, assessment, and management. New York: Wiley.

Huang, Z., Kuang, A., Fan, W., \& Zhou, Q. (2012). Impact of traveler information on road network travel time reliability. Journal of Transportation Systems Engineering and Information Technology, 12(6), 93-99. http://dx.doi.org/10.1016/S1570-6672(11)60235-3.

Inanloo, B., Tansel, B., Shams, K., Jin, X., \& Gan, A. (2016). A decision aid GlS-based risk assessment and vulnerability analysis approach for transportation and pipeline networks. Safety Science, 84, 57-66. http://dx.doi.org/10.1016/j.ssci.2015.11.018. 
Intergovernmental Panel on Climate Change - IPCC. (2006). IPCC guidelines for national greenhouse gas inventories. Kanagawa: National Greenhouse Gas Inventories Programme, Institute for Global Environmental Strategies.

Jenelius, E., \& Mattsson, L. G. (2012). Road network vulnerability analysis of area-covering disruptions: a grid-based approach with case study. Transportation Research Part A, Policy and Practice, 46(5), 746-760. http://dx.doi.org/10.1016/j.tra.2012.02.003.

Jenelius, E., Petersen, T., \& Mattsson, L. G. (2006). Importance and exposure in road network vulnerability analysis. Transportation Research Part A, Policy and Practice, 40(7), 537-560. http://dx.doi.org/10.1016/j.tra.2005.11.003.

Karim, A., \& Adeli, H. (2002). Incident detection algorithm using wavelet energy representation of traffic patterns. Journal of Transportation Engineering, 128(3), 232-242. http://dx.doi.org/10.1061/(ASCE)0733-947X(2002)128:3(232).

Kermanshah, A., \& Derrible, S. (2016). A geographical and multi-criteria vulnerability assessment of transportation networks against extreme earthquakes. Reliability Engineering \& System Safety, 153, 39-49. http://dx.doi.org/10.1016/j.ress.2016.04.007.

Knoop, V. L., Hoogendoorn, S. P., \& van Zuylen, H. J. (2007). Approach to critical link analysis of robustness for dynamical road networks. In A. Schadschneider, T. Pöschel, R. Kühne, M. Schreckenberg \& D. E. Wolf (Eds.), Traffic and granular flow’05 (pp. $393-$ 402). Heidelberg: Springer. http://dx.doi.org/10.1007/978-3-540-47641-2_35.

Knoop, V. L., Snelder, M., van Zuylen, H. J., \& Hoogendoorn, S. P. (2012). Link-level vulnerability indicators for real-world networks. Transportation Research Part A, Policy and Practice, 46(5), 843-854. http://dx.doi.org/10.1016/j.tra.2012.02.004.

Luathep, P., Sumalee, A., Ho, H. W., \& Kurauchi, F. (2011). Large-scale road network vulnerability analysis: a sensitivity analysis based approach. Transportation, 38(5), 799-817. http://dx.doi.org/10.1007/s11116-011-9350-0.

Lyons, G., \& Davidson, C. (2016). Guidance for transport planning and policymaking in the face of an uncertain future. Transportation Research Part A, Policy and Practice, 88, 104-116. http://dx.doi.org/10.1016/j.tra.2016.03.012.

Mattsson, L. G., \& Jenelius, E. (2015). Vulnerability and resilience of transport systems: a discussion of recent research. Transportation Research Part A, Policy and Practice, 81, 16-34. http://dx.doi.org/10.1016/j.tra.2015.06.002.

Muriel-Villegas, J. E., Alvarez-Uribe, K. C., Patiño-Rodríguez, C. E., \& Villegas, J. G. (2016). Analysis of transportation networks subject to natural hazards: insights from a Colombian case. Reliability Engineering \& System Safety, 152, 151-165. http://dx.doi. org/10.1016/j.ress.2016.03.006.

Myhre, G., Shindell, D., Bréon, F.-M., Collins, W., Fuglestvedt, J., Huang, J., Koch, D., Lamarque, J.-F., Lee, D., Mendoza, B., Nakajima, T., Robock, A., Stephens, G., Takemura, T., \& Zhang, H. (2013). Anthropogenic and natural radiative forcing. In T. F. Stocker, D. Qin, G. K. Plattner, M. Tignor, S. K. Allen, J. Boschung, A. Nauels, Y. Xia, V. Bex \& P. M. Midgley (Eds.), Climate change 2013: the physical science basis. Contribution of Working Group 1 to the Fifth Assessment Report of the Intergovernmental Panel on Climate Change (pp. 659-740). Cambridge: Cambridge University Press.

Nagpure, A. S., Sharma, K., \& Gurjar, B. R. (2013). Traffic induced emission estimates and trends (2000-2005) in megacity Delhi. Urban Climate, 4, 61-73. http://dx.doi.org/10.1016/j.uclim.2013.04.005.

Romero-Lankao, P., \& Dodman, D. (2011). Cities in transition: transforming urban centers from hotbeds of GHG emissions and vulnerability to seedbeds of sustainability and resilience: Introduction and Editorial overview. Current Opinion in Environmental Sustainability, 3(3), 113-120. http://dx.doi.org/10.1016/j.cosust.2011.02.002.

Scott, D. M., Novak, D. C., Aultman-Hall, L., \& Guo, F. (2006). Network Robustness Index: a new method for identifying critical links and evaluating the performance of transportation networks. Journal of Transport Geography, 14(3), 215-227. http://dx.doi. org/10.1016/j.jtrangeo.2005.10.003.

Sullivan, J. L., Novak, D. C., Aultman-Hall, L., \& Scott, D. M. (2010). Identifying critical road segments and measuring system-wide robustness in transportation networks with isolating links: a link-based capacity-reduction approach. Transportation Research Part A, Policy and Practice, 44(5), 323-336. http://dx.doi.org/10.1016/j.tra.2010.02.003.

Tampère, C. M. J., Stada, J., Immers, B., Peetermans, E., \& Organe, K. (2008). Methodology for identifying vulnerable sections in a national road network. Transportation Research Record: Journal of the Transportation Research Board, 2012(1), 1-10. http://dx.doi. $\operatorname{org} / 10.3141 / 2012-01$.

Taylor, M. A., Sekhar, S. V., \& D’Este, G. M. (2006). Application of accessibility-based methods for vulnerability analysis of strategic road networks. Networks and Spatial Economics, 6(3-4), 267-291. http://dx.doi.org/10.1007/s11067-006-9284-9.

Thomé, A. M. T., Scavarda, L. F., \& Scavarda, A. J. (2016). Conducting systematic literature review in operations management. Production Planning and Control, 27(5), 408-420. http://dx.doi.org/10.1080/09537287.2015.1129464.

Thorisson, H., \& Lambert, J. H. (2017). Multiscale identification of emergent and future conditions along corridors of transportation networks. Reliability Engineering \& System Safety, 167, 255-263. http://dx.doi.org/10.1016/j.ress.2017.06.005.

Transportation Research Board - TRB. (1998). Travel estimation techniques for urban planning (NCHR Report, 365). Washington: TRB.

Wang, X. (2005). Integrating GIS, simulation models, and visualization in traffic impact analysis. Computers, Environment and Urban Systems, 29(4), 471-496. http://dx.doi.org/10.1016/j.compenvurbsys.2004.01.002.

Yin, Y., \& Lawphongpanich, S. (2006). Internalizing emission externality on road networks. Transportation Research Part D, Transport and Environment, 11(4), 292-301. http://dx.doi.org/10.1016/j.trd.2006.05.003. 